\title{
Perfil hematológico de cães naturalmente infectados por Leishmania chagasi
}

Michel Muálem de Moraes Alves ${ }^{1}$, Ivete Lopes de Mendonça ${ }^{2}$, Joilson Ferreira Batista ${ }^{3}$, Fernanda Samara Barbosa Rocha ${ }^{1}$, Esther Machado de Carvalho e Silva ${ }^{4}$

\author{
${ }^{1}$ Médico Veterinário Residente em Doenças Parasitárias do Laboratório de Sanidade Animal, Universidade \\ Federal Do Piauí, \\ ${ }^{2}$ Professora Doutora de Doenças Parasitárias dos Animais Domésticos, Universidade Federal do Piauí \\ ${ }^{3}$ Mestrando em Ciência Animal, Universidade Federal do Piauí \\ ${ }^{4}$ Médica Veterinária Residente em Patologia Clínica do Laboratório de Patologia Clínica Animal, Hospital \\ Veterinário Universitário da Universidade Federal do Piauí \\ *Autor para correspondência, E-mail: mualemmichel@hotmail.com
}

\begin{abstract}
RESUMO. O objetivo deste trabalho foi avaliar o perfil hematológico de cães com diagnóstico sorológico e parasitológico positivos para LVC. Foram utilizados 130 cães adultos sem distinção de sexo e/ou raça, animais estes, submetidos a exames clínicos onde se verificava ou não a presença de sintomas para a doença. Sendo os animais classificados em assintomáticos, oligossintomáticos e sintomáticos. O diagnóstico definitivo foi baseado em testes sorológicos (TR DPP ${ }^{\circledR}$ ) e parasitológicos (esfregaço direto corado com Giemsa e meio de cultura NNN enriquecido com Schneider's utilizando amostras de medula e linfonodo e, nos animais com lesão de pele, raspado da borda da lesão o qual foi distendidos em lâmina e corado com Giemsa). Os animais com calazar apresentaram anemia normocíticanormocrômica, presença de roleaux eritrocitário, trombocitopenia, linfopenia e eosinopenia.
\end{abstract}

Palavras chaves: LVC, alterações hematológicas, cães

\section{Hematological profile in dogs naturally infected with Leishmania chagasi}

\begin{abstract}
The objective of this study was to evaluate the hematological profile of dogs with diagnosis parasitological and serological positive for LVC. 130adult dogs without distinction of sex or race were used; these animal sunder were clinical examinations where there was the presence or absence of symptoms for LVC. The animals were classified as asymptomatic, oligosymptomatic and symptomatic. The final diagnosis was based on serological tests (TR DPP ${ }^{\circledR}$ ) and parasitological (directsmear stained with Giemsa and medium culture NNN enriched with Schneider's). Using samples of bone marrow and lymph nodes, and in animals with lesions of the skin, scraping theedge of the lesion which was stretched on slides and stained with Giemsa). Animals with leishmaniasis showed normocytic normochromic anemia presence of erythrocyte eroleaux, thrombocytopenia, lymphopenia and eosinopenia.
\end{abstract}

Keywords: LVC, hematological changes, dogs

\section{Introdução}

A leishmaniose visceral canina (LVC), também conhecida Como calazar é uma doença que acomete inúmeras espécies animais, incluindo o homem. É causada na América Latina pelo protozoário Leishmania (Leishmania) infantum chagasi, um parasita intracelular de células mononucleares (Maurício et al., 1999; Camargo et al., 2007).

A transmissão se dá através da picada da fêmea de insetos hematófagos, comumente denominado de flebotomíneo do gênero Lutzomia, tendo como espécies transmissoras o Lutzomyia longipalpise Lutzomyia cruzi (Missawa \& Lima, 2006). O cão doméstico é considerado o principal reservatório da doença (Palantnik-de-Sousa et al., 2001).

Entre as alterações clínicas mais frequentes da doença destacam-se alterações dermatológicas, onicogrifose, linfadenopatia, esplenomegalia, hiporexia e apatia. (Cavalcanti et al., 2005; Caminha \& Soto-Blanco, 2008). Mediante as 
grandes quantidades de sintomatologias clínicas inespecíficas, é importante a obtenção de conhecimentos detalhados de outros parâmetros: como através da análise de exames laboratoriais (Coutinho, 2005).

Os parâmetros hematológicos são úteis para avaliar, sobretudo operfil clínico do animal, ao mesmo tempo em que nos permite obter informações acerca do desenvolvimento da resposta imunitária.Os achados hematológicos mais constantes são anemia normocíticanormocrômica (Reis et al., 2006) e trombocitopenia (Ciaramella et al., 2005). Em Teresina-PI, área endêmica para LVC, há poucos trabalhos referentes às alterações hematológicas relacionadas ao caráter da doença, assim o presente trabalho teve por objetivo avaliar o perfil hematológico de cães naturalmente infectados por leishmaniose visceral no município de Teresina, Piauí.

\section{Material e Métodos}

Foram utilizados 130 cães adultos, sem distinção de sexo e raça, atendidos no HVU (Hospital Veterinário Universitário) da Universidade Federal do Piaú (UFPI). Estes animais foram submetidos à realização de exame de calazar no Laboratório de Sanidade Animal (LASAN-UFPI). Foram realizados exames clínicos onde se observava a presença ou não de sintomas para LVC, de acordo com Mancianti et al. (1988) foram categorizados em assintomáticos $(n=32)$, oligossintomáticos $(n=48)$ e sintomáticos $(\mathrm{n}=50)$.

Para a realização do teste sorológico TR DPP ${ }^{\circledR}$ foi coletado sangue da veia jugular em tubo a vácuo de $4 \mathrm{~mL}$ sem anticoagulante, centrifugados a $2000 \mathrm{rpm}$ por dez minutos para a obtenção do soro. O TR DPP ${ }^{\circledR}$ foi feito seguindo o protocolo de recomendação do fabricante. Para a realização do hemograma, foi coletado sangue da veia jugular em tubo a vácuo de $4 \mathrm{ml}$ com anticoagulante (EDTA). O eritrograma foi realizado utilizando aparelho automatizado Abc Vet $^{\circledR}$ e kit vet Pack ${ }^{\circledR}$. A contagem diferencial de leucócitos foi feita em lâminas de esfregaço sanguíneo coradas com GIEMSA e observadas ao microscópio óptico na objetiva de 100x no exame de cem células leucocitárias.

Para o diagnóstico da doença foram realizados exames parasitológicos: punção de medula e aspiração de linfonodos em todos os animais incluídos no estudo e biópsia na borda da lesão nos animais com lesão de pele. Materiais estes, confeccionados através da distensão em lâminas que foram posteriormente coradas com Giemsa, para a detecção de formas amastigotas do parasita. Também foi realizado como método parasitológico a semeadura de aspirado da medula e linfonodos poplíteos em meio de cultura NNN enriquecido com Schneider's incubados a $26^{\circ} \mathrm{C}$ em estufa BOD com intervalos de leitura de 5,7 e 9 dias após a coleta, para a detecção de formas promastigotas.

Foram considerados positivos somente aqueles animais que apresentaram teste sorológico e parasitológico positivo e com sintomatologia aparente (divididos em oligossintomáticos e sintomáticos). Para o grupo controle foram utilizados animais assintomáticos e negativos nos testes utilizados neste trabalho para diagnóstico da LVC.

As análises estatísticas foram feitas através do teste de Kruskal Wallis $(p>0,05)$ e teste exato de Fisher's $(\mathrm{p}<0,05)$, utilizando o programa Gram Padprism $^{\circledR}$ versão 5.0.

\section{Resultados e Discussão}

Os resultados encontrados foram: diminuição da quantidade de eritrócitos, no hematócrito, no volume globular médio, nos eosinófilos e nos linfócitos dos animais positivos em relação aos animais negativos, sendo ainda mais agravante nos animais sintomáticos (Tabela 1).

Observaram-se ainda como alterações morfológicas e/ou numéricas no hemograma de cães naturalmente infectados por Leishmaniasp.: anemia normocíticanormocrômica, trombocitopenia, presença de roleaux e eosinofilia (Tabela 2).

Os resultados da avaliação hematológica corroboram com os descritos por Bush (2004) e Costa-Val et al. (2007). Na LVC a anemia pode ocorrer por diferentes causas-resposta inflamatória por causa da infecção, eritropoese diminuída pelo caráter crônico, perda de sangue, lise de hemácias e diminuição eritrocitária por produção de auto-anticorpos que levam ao sequestro esplênico e hepático (Ikeda-Garcia et al., 2003).

Além de anemia outro achado importante nos animais doentes foi a presença de hemácias em cadeias (roleuax). O rouleaux eritrocitário ocorre devido ao aumento sérico de globulina e a diminuição de albumina, também observado por Feldman et al. (2000). 
Tabela 1. Média e desvio padrão dos parâmetros hematológicos de cães naturalmente infectados por Leishmaniasp.no município de Teresina-PI.

\begin{tabular}{|c|c|c|c|c|}
\hline \multirow{2}{*}{ Parâmetros } & Controle & Oligossintomático & Sintomático & \multirow{2}{*}{ Valores de referência } \\
\hline & $\mathrm{n}=32$ & $\mathrm{n}=48$ & $\mathrm{n}=50$ & \\
\hline Hemácia $\left(\right.$ x $\left.10^{6} / \mathrm{mm} 3\right)$ & $6,58 \pm 2,28^{a}$ & $5,05 \pm 1,02^{\mathrm{b}}$ & $4,30 \pm 1,00^{\mathrm{c}}$ & $5,5-8,5$ \\
\hline Hematócrito (\%) & $42,24 \pm 6,67^{\mathrm{a}}$ & $32,04 \pm 7,11^{\mathrm{b}}$ & $27,74 \pm 6,22^{\mathrm{c}}$ & $37-55$ \\
\hline Hemoglobina (g\%) & $15,29 \pm 2,88^{\mathrm{a}}$ & $10,65 \pm 2,66^{\mathrm{b}}$ & $9,17 \pm 2,20^{\mathrm{c}}$ & $12-18$ \\
\hline VGM (fl) & $68,03 \pm 3,48^{\mathrm{a}}$ & $63,38 \pm 4,21^{\mathrm{b}}$ & $65,10 \pm 6,01^{\mathrm{b}}$ & $60-77$ \\
\hline CHGM (\%) & $35,99 \pm 2,33^{\mathrm{a}}$ & $33,05 \pm 2,28^{\mathrm{b}}$ & $32,78 \pm 2,47^{\mathrm{b}}$ & $32-36$ \\
\hline Plaquetas $\left(/ \mathrm{mm}^{3}\right)$ & $233,9 \pm 80,2^{\mathrm{a}}$ & $193,2 \pm 122,8^{\mathrm{a}}$ & $231,3 \pm 120,7^{\mathrm{a}}$ & $200-500$ \\
\hline Leucócitostotais $\left(/ \mathrm{mm}^{3}\right)$ & $13950 \pm 7817^{\mathrm{a}}$ & $10280 \pm 4287^{\mathrm{a}}$ & $12520 \pm 7699^{\mathrm{a}}$ & $6.000-17.000$ \\
\hline Eosinófilos $\left(/ \mathrm{mm}^{3}\right)$ & $1056,0 \pm 896,8^{a}$ & $620,8 \pm 752,6^{\mathrm{b}}$ & $599,0 \pm 766,3^{\mathrm{b}}$ & $100-1.250$ \\
\hline Segmentados $\left(/ \mathrm{mm}^{3}\right)$ & $9493 \pm 6496^{\mathrm{a}}$ & $6564 \pm 3587^{\mathrm{a}}$ & $9086 \pm 6864^{\mathrm{a}}$ & $3.000-11.500$ \\
\hline Linfócitos $\left(/ \mathrm{mm}^{3}\right)$ & $3094 \pm 1998^{\mathrm{a}}$ & $2403 \pm 1405^{\mathrm{ab}}$ & $2193 \pm 2007^{b}$ & $1.000-4.800$ \\
\hline Monócitos $\left(/ \mathrm{mm}^{3}\right)$ & $342,3 \pm 414,6^{\mathrm{a}}$ & $366,5 \pm 360,0^{\mathrm{a}}$ & $390,3 \pm 434,6^{\mathrm{a}}$ & $150-1.350$ \\
\hline
\end{tabular}

Letras iguais na linha não diferem pelo teste de Kruskal Wallis ( $>>0,05)$. Valores de referência segundo Meyer e Harvey (2004)

Tabela 2. Alterações morfológicas e/ou numéricas observadas no hemograma de cães naturalmente infectados por Leishmania sp.

\begin{tabular}{llccc}
\hline Alterações & & Infectados & Não infectados & p-valor \\
\hline \multirow{2}{*}{ Anemia } & Sim & 75 & 5 & $<0,0001^{*}$ \\
& Não & 23 & 27 & $<0,0001^{*}$ \\
Anemia normocíticanormocrômica & Sim & 53 & 3 & $0,0227^{*}$ \\
Rouleaux & Não & 45 & 29 & $0,0070^{*}$ \\
Eosinofilia & Sim & 25 & 2 & 30 \\
& Não & 73 & 10 & $0,0057^{*}$ \\
\hline
\end{tabular}

* Estatisticamente significativo no teste Exato de Fisher's $\mathrm{p}<0,05$.

Animais com LVC apresentando trombocitopenia também foram descritos por Medeiros (2008) que observou em 53,1\% dos cães reagentes no seu estudo. A ocorrência de trombocitopenia em cães com LV é devido a presença de alteração na parede vascular por vasculite causada porimunocomplexos circulantes (Feldman et al., 2000). Outro mecanismo na diminuição do número de plaquetas na $\mathrm{LV}$ pode estar associado à presença de imunoglobulinas anti-plaquetas (Terrazano et al., 2006), descrita em 63,3\% dos cães naturalmente infectados por $L$. infantum (Ciaramella et al., 2005).

Ao se avaliar o estudo dos leucócitos o presente trabalho demonstrou não haver diferença significativa entre os grupos. Medeiros (2008), encontrou resultados semelhantes onde a leucometria de cães reagentes se apresentavam dentro da normalidade $\left(12.574,15 \mathrm{~mm}^{3}\right)$, o que corrobora também com estudos anteriores de Ikeda-Garcia et al. (2003) e Costa-Val et al. (2007). Em relação à contagem diferencial de leucócitos, leva-se em consideração que o comportamento leucocitário varia com alguns fatores como: status imunológico, severidade dos sinais clínicos, associação com quadros infecciosos, dentre outros (Ikeda-Garcia et al., 2007). Neste contexto, a alteração leucocitária mais presente foi linfopenia observada nos animais oligossintomáticos e sintomáticos, igualmente observada por Mattos J et al. (2004). $\mathrm{Na}$ LV a linfopenia ocorre devido ao 
confinamento temporário dos linfócitos no baço e/ou linfonodos enquanto assim, respondem ao agente infeccioso ou pela destruição destas células pela própria Leishmania (Bush, 2004).

Eosinofilia foi a segunda alteração leucocitária presente nos animais com LVC. Resultados semelhantes foram encontrados por Jain (1993) onde a presença de sinais dermatológicos e a ocorrência de outros parasitas podem contribuir para o aumento na produção de eosinofilos nestes animais. Enquanto que a eosinopenia pode ser em ocorrência da condição de estresse mediado por cortisol, possivelmente estes dois mecanismos ocorrem simultaneamente e em grau variável (Jain 1993).A avaliação de um perfil clínico e/ou laboratorial é perfeitamente viável para o esclarecimento da evolução da doença no cão e elaboração de um prognóstico. Além disso, em áreas endêmicas para LVC esse perfil pode ser sugestivo da doença.

\section{Conclusão}

Cães com LVC possuem como alterações hematológicas anemia normocítica normocrômica, trombocitopenia, presença de rouleaux e eosinofilia.

\section{Referências Bibliográficas}

Bush, B. M. Interpretação de resultados Laboratoriais para Clínicos de Pequenos Animais. São Paulo. Roca, 2004, 376p.

Camargo J.B.; Trocarelli, M.Z.; Ribeiro, M.G. \& Langoni H. 2007. Canine visceral leishmaniosis: aspects of public health and control. Clínical Veterinary 12: 86-92.

Caminha, A.E.Q. \& Soto-Blanco B. 2008. Aspectos clínicos da leishmaniose visceral canina na cidade de Fortaleza, CE. Archive Veterinary Science. 13: 218-222.

Cavalcanti, M. P.; Faustino, M. A. G.; Silva L.B.G. \& Alves, L.C. 2005. Aspectosdas dermatopatias infecciosas e parasitárias em cães com diagnóstico presuntivo de leishmaniose visceral. Clínica Veterinária, 58:36-42.

Ciaramella, P.; PelagalliI, A.; Cortese, L.; Pero, M.E.; Corona, M.; Lombardi, P.; Avallone, L. \& Persehino, A. Altered platelet aggregation and coagulation disorders related to clinical findings in 30 dogs naturally infected by Leishmania infantum. The Veterinary Journal, 169: 465-467, 2005.
Costa-Val, A. P.; Cavalcanti, R. R. D.; Figueiredo -Gontijo N.; Michalick, M.S.; Alexander, B.; Williams, P. \& Melo, M.N. Canine visceral leishmaniasis: relationships between clinical status, humoral immune response, haematology and Lutzomyia (Lutzomyia) longipalpis infectivity. The Veterinary Journal 2007; 174: 636-643.

Coutinho, J.F.V. Estudo clínico-laboratorial e histopatológico de cães naturalmente infectados por Leishmania chagasi com diferentes graus de manifestação física. Dissertação (Mestrado) - Universidade Federal do Rio Grande do Norte - UFRN, 2005.

Feldman, B.V.; Zinkl, J.G.; Jain, N.C. Schalm's. Veterinary Hematology. Canada: Lippincott Willians \& Wilkins, 2000, 1344p.

Ikeda-Garcia, F.A. \&Marcondes, M. 2007. Métodos de diagnóstico da leishmaniose visceral canina. Clínica Veterinária. 71:34-42.

Jain, N.C. Essentials of veterinary hematology. Philadelphia: Lea \&Febiger, 1993. 417p.

Mancianti, F.; Gramiccia, M. \&Gradoni, L.E. T. Studies on canine control. Evolution of infection of different clinical forms of canine leishmaniasis following antimonial treatment. Transactions of the Royal Society of Tropical Medicine and Hygiene, v. 82, p. 566-567, 1988.

Mattos, J. R.; D. G.; Pinheiro, J. M.; Meneses, R. C. \&Costa, D. A. Aspectos e de laboratório de cães soropositivos para leishmaniose. Arquivo Brasileiro de Medicina Veterinária $e$ Zootecnia, v. 56, n. 1, p. 119-122, 2004.

Maurício, I. L.; Howard, M. K.;Stothard, J.R. \& Miles, M.A. 1999. Genomic diversity in the Leishmania donovani complex. Parasitology, 119: (Pt3):237-246.

Medeiros, C. M. O.; Melo, A. G. C.; Lima, I. M. A.; Silva, I. N. G.; Oliveira, L. C. \&Silva, M. C. Perfil hematológico de cães com leishmaniose visceral no município de Fortaleza, Ceará. Ciência Animal, 18(1):4350, 2008.

Meywe, D.J. \& Harvey, J.W. Veterinary laboratory medicine: interpretation \& diagnosis. 2.ed. Philadelphia: Sauders, 2004. $351 \mathrm{p}$. 
Missawa, N.A. \& Lima, G.B.M. 2006. Distribuição espacial de Lutzomyia longipalpis (Lutz \& Neiva, 1912) e Lutzomyia cruzi (Mangabeira, 1938) no estado de Mato Grosso. Revista Sociedade Brasileira Medicina Tropical, 34:337-340.

Palatnik-de-Sousa, C. B.; Santos, W. R.; FrançaSilva, J. C.; Costa, R.T. \& Reis, A. B.; Palatnik, M.; Myrink, W. \& Genaro, O. 2001. Impact of canine control on the epidemiology of canine and human visceral leishmaniasis in Brazil. The American Journal of Tropical Medicine and Hygiene. 65:510-517.

Reis, A. B; Martins-Filho, O. A.; TeixeiraCarvalho, A.;Carvalho, M. G.;Mayrink, W.; França-Silva, J. C.; Giunchetti, R. C.; Genaro, O. \& Corrêa-Oliveira, R. Parasite density and impaired biochemical/hematological status are associated with severe clinical aspects of canine visceral leishmaniasis. Revista Veterinary Science 2006; 81: 68-75.
Terrazano, O. G.; Coertese, L.; Piantedose, D.; Zappacosta, S.; Diloria, A.; Santoro, D.; Ruggiero, G. \& Cuaramella, P. Presence of anti-platelet IgM and IgG antibodies in dogs naturally infected by Leishmania infantum. Veterinary Immunology and Immunopathology, 110(3-4): p. 331-337, 2006.

\section{Recebido em Julho 15, 2014}

Aceito em Setembro 3, 2014

License information: This is an open-access article distributed under the terms of the Creative Commons Attribution License, which permits unrestricted use, distribution, and reproduction in any medium, provided the original work is properly cited. 